\title{
A phenetic analysis of Philippine Rubus species (Rosaceae) by morphology
}

\author{
Mark Stephen B. Real ${ }^{1,2}$, Domingo A. Madulid ${ }^{1}$
}

\begin{abstract}
The taxonomy of the Philippine Rubus species was studied through a phenetic analysis of the morphological data from preserved specimens. After recording the character states, the data were analyzed using cluster analysis and PCA, and the resulting analysis allowed the delimitation of morphologically similar Rubus species. Specimens of the Rubus genus collected in the country were separated into two clusters distinguished by leaf structure. Specimens of the same species are often found in multiple sub-clusters, which suggests the high degree of variation within a species. PCA of morphological data from Rubus species show that leaf and floral characters, which include the maximum number of lobes, pedicel pubescence, outside pubescence of the hypanthium, apex of the simple leaf blade, and the apical process of the sepals, explain the variation in Rubus species in the Philippines.
\end{abstract}

Keywords: cluster analysis, brambles, Rosaceae, PCA

\section{Introduction}

Rubus is a morphologically diverse genus with at least 500 species (Alice and Campbell, 1999; Carter et al, 2019, Huang and $\mathrm{Hu}, 2009$; $\mathrm{Lu}$ and Boufford, 2003) classified into 12 to 15 subgenera (Jennings, 1988; Hummer, 1996; Holub, 1997; Howarth et al., 1997; Alice and Campbell, 1999; and Marulanda et al., 2012). The plant genus is more commonly called wild brambles and commercially marketed as raspberries and blackberries (Hummer, 1996). In the Philippines, Rubus is more commonly known as sapinit or pinit. A recent study showed that the species may have originated from North America, and it was only later distributed to Asia and Europe. Moreover, only two of the subgenera are monophyletic, while the rest are either polyphyletic or paraphyletic (Carter et al., 2019). It is more common and more diverse in the temperate regions, and in addition to natural speciation, diversity of the genus also increased through artificial breeding programs aimed to produce commercially and agriculturally viable varieties of Rubus (Hummer, 1996).

The Philippines has a considerable diversity of the genus.

\begin{tabular}{l}
\hline${ }^{1}$ Biology Department, College of Science, De La Salle University \\
${ }^{2}$ Natural Science Department, College of Arts and Sciences, Our Lady \\
of Fatima University \\
*Corresponding email: mbreal@fatima.edu.ph \\
Date Submitted: 01 October 2019 \\
Date Accepted: 26 February 2020
\end{tabular}

Kalkman (1993) reported seventeen species of Rubus in the Philippines, six of which are endemic. Previous works on Rubus were published by A.D.E. Elmer and E.D. Merrill during the American period (Elmer, 1908; Elmer, 1939; Elmer and Focke, 1913; Merrill, 1918; Merrill, 1922). In his revision of the genus Rubus L., Kalkman (1993) reduced several species described by Elmer and Merrill into synonyms of other previously published species as he noted that it is possible to accept certain ranges of variability within descriptions of the species (Kalkman, 1984).

A common concern among Rubus species is its ability to quickly hybridize and its ability to undergo apomixis, a form of asexual reproduction characterized by the development of the ovule into a seed without fertilization (Sarhanova et al., 2017). To resolve this concern, Weber (1996) noted that taxonomists may consider apomicts as species as long as the organisms are considered well stabilized and are widely distributed. While not as prevalent, previous researchers noted that Rubus plants in the Philippines may also undergo hybridization (Focke, 1914, Kalkman, 1993, Zandee and Kalkman, 1981), although this problem is not as prevalent compared to the European Rubus species (Kalkman, 1993).

After Kalkman's study in 1993, later projects on the Philippine flora may have affected the taxonomic classification of Rubus in the Philippines, an example of which is the Flora of the Philippines project. The project involved a comprehensive collection of plant specimens throughout the country (Madulid and Sohmer, 1997). The researchers involved in the project may have collected samples that could provide additional information useful for studying the diversity of Rubus species in the Philippines. The morphological data can be used to delimit the 
species with the help of cluster analysis, while Principal Component Analysis can be used to identify characters that are important in classifying the different Rubus species.

\section{Methodology}

\section{Acquisition of Study Materials}

Herbarium specimens from the Philippine National Herbarium (PNH), the University of the Philippines Los Baños Museum of Natural History (CAHUP and LBC), the Central Mindanao University Herbarium (CMUH), the University of Sto. Tomas Herbarium (USTH), University of the Philippines Diliman Herbarium (PUH), and De La Salle University Herbarium (DLSUH) were examined. Photographs of the type specimens obtained from the digital collections of Royal Botanical Garden Kew (K), Geneva Herbaria (G), New York Botanical Garden (NY), Arnold Arboretum (A), Museum National d' Histoire Naturelle Paris (P), National Herbarium of Netherlands Leiden (L), National Herbarium of Netherlands Utrecht (U), The Linnean Herbarium (LINN), Herbarium Berolinense (B), and United States National Herbarium (US) were also examined. As much as possible, these specimens were examined in high-resolution digital form. In the digital format of herbarium specimens, the specimen barcodes and herbarium or collector's numbers were noted to track the herbarium specimens. Only preserved specimens with both leaves and inflorescences or fruits were used in this study.

\section{Data Measurement and Analysis}

Morphological characters were classified into two types: qualitative or quantitative variables. Qualitative states were described based on those used in previous monographs and revisions (Kalkman, 1993). For each quantitative trait, five measurements were made from randomly selected plant parts. The qualitative and quantitative characters were examined using dissecting microscopes, magnifying glasses, Vernier calipers, and rulers. In case of missing morphological characters, protologues of species were first consulted to ensure that the specimen, based on initial identification, lacks the character being studied. Once it is confirmed through protologues and previous literature, missing data will be filled out through the average of all the groups (mean imputation). Among the specimens wherein imputing scores was required is with the specimen of $R$. clementis (RCL1), several specimens of $R$. rosifolius and $R$. fraxinifolius, and specimen of $R$. tagallus (RTA1), which some floral characters were not observable due to the available specimens only featuring buds. Removing the samples that underwent data imputation did not alter the conclusions reached in this study.
A total of 57 discrete and continuous morphological characters were observed. These character states were tabulated in a matrix (Table 1), and information from this matrix is used to describe similar species.

\section{Phenetic Analysis}

Identification of specimens were based on available keys, type specimens, and literature on the Philippine Rubus species. Character states were coded for numerical analysis. A total of 289 specimens were inspected for this study.

Cluster analysis was used to analyze the similarities between the species of interest. Phenograms were constructed using UPGMA after clustering analysis using PAST 2.17 (Hammer et al., 2001). Additional analysis of morphological data was performed using PCA, also using PAST 2.17. The analysis provided by both statistical tests provided basis for formulation of taxonomic key and classification.

The characteristics of the different species were collated from herbarium specimens and from the samples observed in the field. This information was used to create a maximum parsimony tree using PAUP*4.0b10 (Swofford, 2001).

\section{Results and Discussion}

A dendrogram resulting from the Cluster Analysis (Figs. 1 and 2) of the morphological data obtained from the specimens of Rubus species in the Philippines shows two main clusters of specimens, and these clusters are separated primarily by their leaf structure. The first cluster (Cluster I) of species primarily have simple leaves, and the second cluster has species with compound leaves. The first cluster (Cluster I) (Fig. 1) is represented by Rubus pectinellus Maxim., R. pyrifolius J.E.Sm., $R$. cumingii Kuntze., $R$. luzoniensis Merr., $R$. perfulvus Merr., $R$. elmeri Focke, $R$. glomeratus B1., $R$. pentalobus Hayata, $R$. rolfei Vidal, $R$. mearnsii Elmer, $R$. moluccanus L., $R$. heterosepalus Merr., $R$. benguetensis Elmer, $R$. edañoii Merr., $R$. sorsogonensis Elmer, and $R$. clementis Merr., the only species in this cluster that has compound leaves. The second cluster (Cluster II) (Fig. 2) is comprised of Rubus copelandii Merr., $R$. fraxinifolius Poir., $R$. rosifolius J.E.Sm., $R$. tagallus Cham. \& Schlecht., $R$. ellipticus J.E.Sm., and $R$. niveus Thunb.

The dendrogram created by the cluster analysis was able to separate the species previously classified under the subgenus Ideobatus (Kalkman, 1993) from the rest of the Rubus species present in the Philippines. This subgenus includes species that have at least five pinnately arranged leaflets and terminal thyrse (Kalkman, 1987). On the other hand, $R$. pectinellus and $R$. pentalobus which were earlier classified as part of the subgenus Chamaebatus (Lu and Boufford, 2003), is nestled within the 


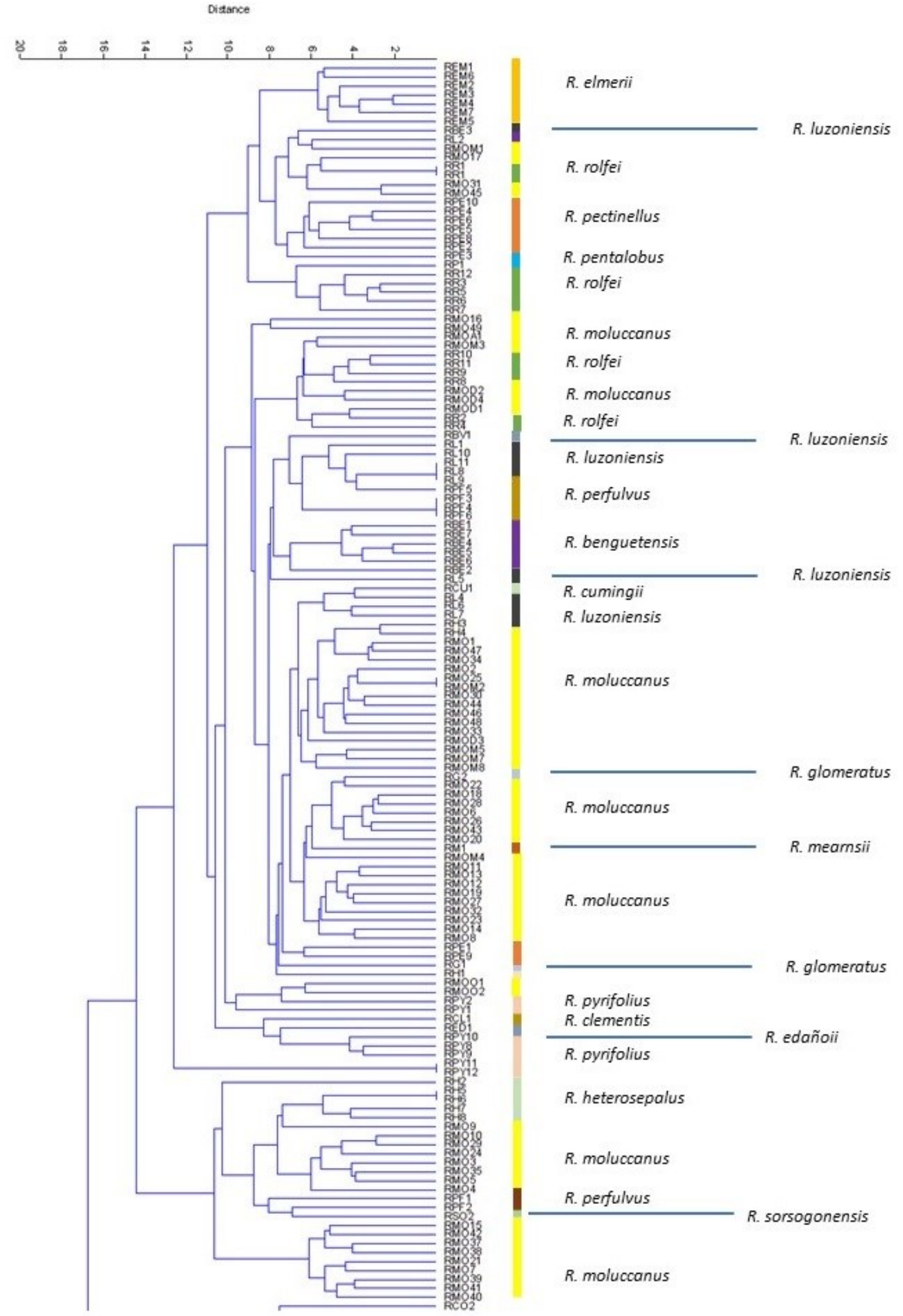

Figure 1. UPGMA Dendrogram based on the phenetic analysis of stem, leaf, fruit, and flower morphology of Philippine Rubus species belonging to Cluster I. 


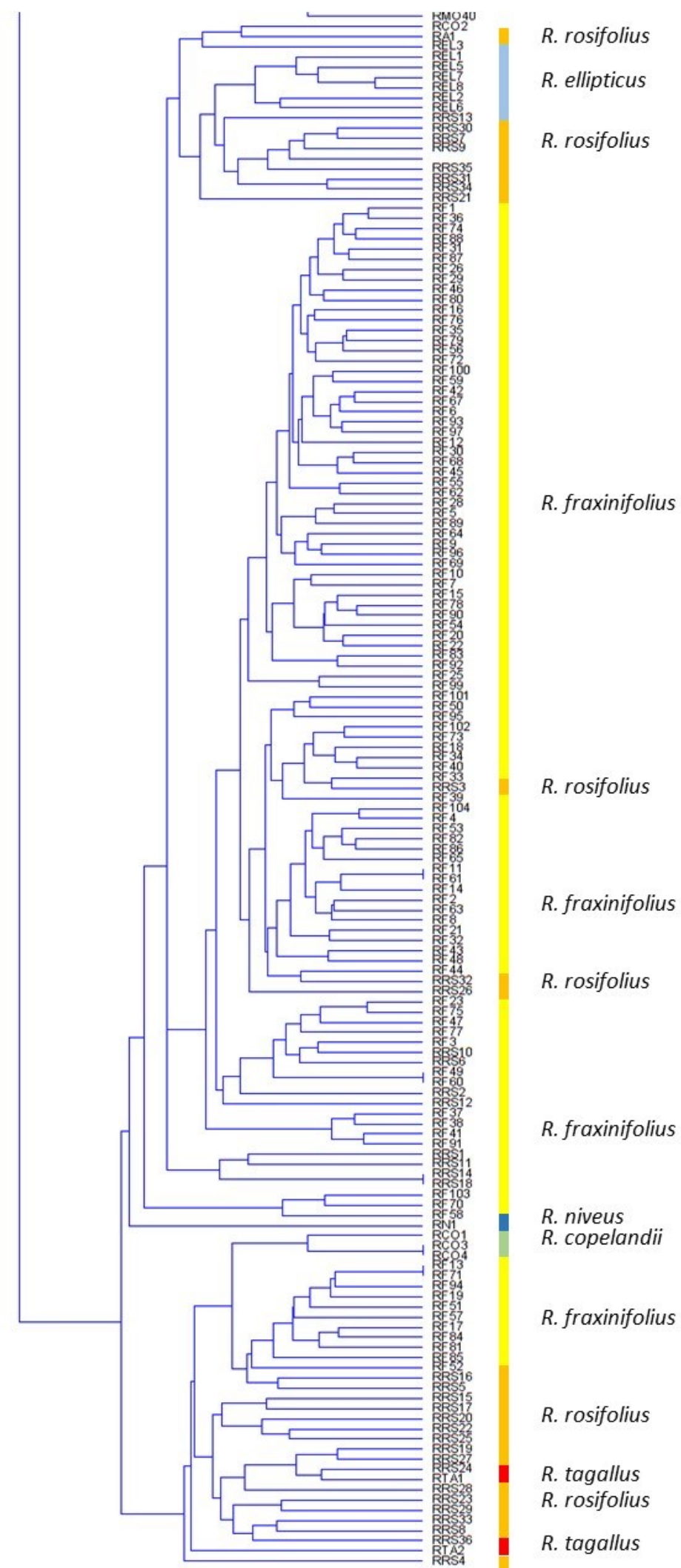

Figure 2. UPGMA Dendrogram based on the phenetic analysis of stem, leaf, fruit, and flower morphology of Philippine Rubus species belonging to Cluster II. 
clade that includes species from the subgenus Malachobatus. Species from both subgenera have simple leaves, although species from subgenus Chamaebatus have needle-like prickles while species from subgenus Malachobatus do not have this feature (Zandee and Kalkman, 1981, Kalkman, 1984, Lu and Boufford, 2013). However, other features did not distinguish between the members of both subgenera. Interestingly, the dendrogram resulting from cluster analysis also included $R$. clementis into the second cluster, which indicates that despite the presence of compound leaves, other features may have contributed to the greater similarity of the species with the specimens with simple leaves.

The dendrogram resulting from the cluster analysis also provided some insight on how to resolve taxonomic issues at the species level. Specimens were temporarily placed into clusters based on Rubus species previously recognized by Merrill (1923) and Kalkman (1992), and the dendrogram showed that while there are some species that can be clearly delineated in the cluster analysis, including $R$. clementis, $R$. mearnsii, and $R$. copelandii, representatives from different species can be found in different sub-clusters.

Cluster II only includes species with compound leaves, and based on the dendrogram, most of the specimens of $R$. fraxinifolius are grouped together into one sub-cluster. Specimens of $R$. rosifolius was found across several subclusters, albeit adjacent, which is indicative of the morphological variability of the species. Previous researchers already highlighted the need to study the species using other potential sources of information (Huang and $\mathrm{Hu}, 2009$ ). $R$. tagallus, one of the species that Zandee and Kalkman (1981) reduced as a synonym of $R$. rosifolius, is found in separate subclusters. This arrangement could reflect the similarities in the vegetative features, which may have heavily influenced the clustering of specimens in the dendrogram. The two species differ primarily in terms of habit and inflorescence, which traits are not included in the analysis due to lack of information in some of the samples. Aside from additional character traits, other sources of information like molecular data and cytological data could be used to better delimit the two taxa.

One sub-cluster, on the other hand, contains several specimens of $R$. copelandii. This species features trifoliate elliptical compound leaves and presence of prickles at the hypanthium. Its close proximity to $R$. fraxinifolius highlights the morphological similarity between the two species. Other species that are also included in Cluster II are R. ellipticus, which have orbicular leaves and bristles along stems and hypanthium, and $R$. niveus, which have white-colored pubescence at the abaxial side of the leaf blade. $R$. ellipticus specimens form a sub-cluster, while the single $R$. niveus specimen studied is placed separate from other species of subgenus Ideobatus.

The first cluster (Cluster I) is comprised of specimens with simple leaves, and these specimens represent species from the subgenera Malachobatus and Chamaebatus. However, there are notably two sub-clusters observed. The key difference between the two sub-clusters is the difference in the length and width of leaves. One of the sub-clusters feature specimens that have leaf lengths $<14 \mathrm{~cm}$ and leaf widths $<10 \mathrm{~cm}$.

Specimens from the same species are often found on both sub-clusters. For example, R. moluccanus, a widely distributed species with four recognized varieties in the Malesian region (Kalkman, 1984) are present in both sub-clusters, which could be explained by the diversity of vegetative and reproductive morphological forms observed in the specimens belonging to the species. Another factor that could contribute to this observation is the presence of numerous samples for R. moluccanus, which may result in the measurement and observation of more polymorphic characters. Other examples of species with specimens in separate clusters are $R$. heterosepalus, a species identified by varying divisions in inner and outer sepals and $R$. perfulvus, a species that features subtruncate leaf bases, saucershaped hypanthium, and entire stipules.

On the other hand, there are species that are found specifically in only one sub-cluster. $R$. cumingii is found in only one sub-cluster along with some specimens from $R$. luzoniensis. Both specimens are noted to have unisexual flowers, although the presence of perfect flowers in at least one specimen of $R$. luzoniensis suggests that the species may be gynodioecious. The two species are separated by the lack of dense pubescence at the abaxial side of $R$. cumingii.

$R$. benguetensis, a species distinguished by the lack of petals, serrate leaf margins, cupular hypanthium, glandular twigs, and entire stipules, also forms its own sub-cluster. However, other species of Rubus that lack petals noticeably do not belong to the same sub-cluster as $R$. benguetensis. $R$. sorsogonensis is distinguished by the absence of sepal teeth, entire stipules, and acuminate leaf apex, while $R$. edañoii have dentate leaf margins, saucer-shaped hypanthium, lack of glandular hairs, and divided stipules. Another trait that distinguishes $R$. edañoii from other species that lack petals is the more elaborate inflorescence, which could explain the presence of $R$. cumingii, a species from the subgenus Micranthobatus, in same sub-cluster in the dendrogram.

$R$. pectinellus, a species that is traditionally assigned to the subgenus Chamaebatus (Lu and Boufford, 2003), formed a subcluster within Cluster I. While it may feature simple leaves, the species differs in terms of its prostate habit and presence of needle-like prickles. Another species that is classified under the subgenus Chamaebatus is $R$. pentalobus, which was found at a 
different sub-cluster compared to R. pectinellus.

The dendrogram may also provide insight into the taxonomic issues of several Malachobatus taxa present in the Philippines. Among the Malachobatus taxa with taxonomic concerns are $R$. rolfei, $R$. pentalobus, and $R$. elmerii. $R$. elmerii was described by W.O. Focke but was later reduced by Kalkman (1984) as a synonym of $R$. rolfei. Meanwhile, $R$. pentalobus was first described by Hayata (1913) as Rubus calycinoides, but like $R$. elmerii, it was also later reduced as a synonym by Kalkman (1984). It was Huang and Hu (2009) who described the taxon as a separate species, and was named $R$. pentalobus, after it was discovered that $R$. calycinoides was already used as a name for another species described by Kuntze in the $19^{\text {th }}$ century.

Based on the dendrogram from cluster analysis, R. elmerii specimens were found in a separate sub-cluster from both $R$. rolfei and $R$. pentalobus specimens. Compared to $R$. rolfei, this species has acute sepal apex, and it also features a more elaborate inflorescence with branches of inflorescence located at the axils of upper leaves. In contrast, $R$. rolfei has a more compact raceme inflorescence with up to six flowers per inflorescence.

Meanwhile, the dendrogram from cluster analysis showed that $R$. pentalobus form a sub-cluster with $R$. rolfei. The two species can be distinguished by their sepal apex. $R$. pentalobus has an acuminate sepal apex while $R$. rolfei has apically incised apex. However, aside from morphological features, cytological evidence could also be used to delimit the taxa. In the case of $R$. pentalobus, Naruhashi et al. (2002) reported that the chromosome number for $R$. pentalobus and $R$. rolfei are different, which provides support for the delimitation of the two taxa.

The last group that was examined separately are the varieties of $R$. moluccanus. Kalkman (1993) organized the Rubus species into four different variants. These varieties are $R$. moluccanus var. moluccanus, R. moluccanus var. discolor (B1.) Kalkm., $R$. moluccanus var. angulosus Kalkm., and $R$. moluccanus var. obtusangulus Miq. These varieties were identified primarily using the number of lobes and the texture of the abaxial pubescence of the leaf blade. However, a cluster analysis using the available morphological data, which excluded the texture of the abaxial surface of the leaf due to difficulty in assessing this character in digital specimens, showed that there is no clear clustering of $R$. moluccanus varieties.

Similar to what is observed among specimens of $R$. moluccanus, the specimens from the different varieties of $R$. moluccanus are found in different sub-clusters. In some occasions, specimens from one variety cluster with specimens from another variety of $R$. moluccanus. For example, a specimen identified as $R$. moluccanus var. angulosus, is clustered with a specimen of $R$. moluccanus var. moluccanus. Meanwhile, specimens of $R$. moluccanus var. discolor and $R$. moluccanus are distributed across different sub-clusters.

The result of cluster analysis may reflect the phenotypic plasticity of the leaves of $R$. moluccanus. Kalkman (1984) discussed the differences between the leaf shapes of the four different variants, and there was considerable variation among the leaf shapes. Kalkman (1984) described two varieties, $R$. moluccanus var. moluccanus and var. discolor, that have two very different leaf shapes and blade division. These descriptions could make it exceedingly difficult for field researchers to identify plant specimens into the different varieties, especially for the non-flowering specimens. Kalkman (1984) added that there are intermediate specimens and dubious cases present between the varieties, which could make it more difficult to properly delimit the taxa.

The PCA of the Philippine Rubus specimens (Fig. 3) also showed two major groupings, and these groupings were also formed on the basis of leaf types displayed by the species. The group of species with compound leaves was distinctly separated from the group of species with simple leaves.

The first two axes of principal components explained $40.10 \%$ of the total variance, with the first axis explaining $32.477 \%$ of the variance while the second axis explaining $7.6261 \%$ of the variance. For the first principal component, the score was influenced by the increasing scores of the maximum number of lobes $(\mathrm{r}=0.9103)$, pedicel pubescence, outside pubescence of the hypanthium, apex of the simple leaf blade, and the apical process of the sepals.

In terms of the number of lobes (Fig. 4), R. elmerii, $R$. glomeratus, $R$. heterosepalus, $R$. mearnsii, $R$. moluccanus, $R$. pectinellus, $R$. perfulvus, and $R$. rolfei, have leaves that may have up to five lobes (Fig. 4a). Meanwhile, $R$. benguetensis, $R$. cumingii, $R$. edañoii, $R$. luzoniensis, $R$. pentalobus, and $R$. sorsogonensis have leaves that may have up to three lobes. The rest of the Rubus species do not have lobed leaves (Fig. 4b).

The score of the second axis, on the other hand, was strongly correlated with the average length and width of the leaf, the average length and width of the fruit, and the length of the leaf blade. In terms of the average length of the leaf $(\mathrm{r}=0.6641)$, $R$. fraxinifolius, $R$. niveus, and $R$. moluccanus have specimens with the longest leaves, while $R$. rolfei, $R$. pectinellus, and $R$. pentalobus have the shortest leaves among the sampled specimens.

PCA was also used to provide further insight in delimiting the different groups of Rubus species that have taxonomic problems (Joly and Bruneau, 2007). One of the groups that were analyzed separately was the group comprised of $R$. tagallus, $R$. 


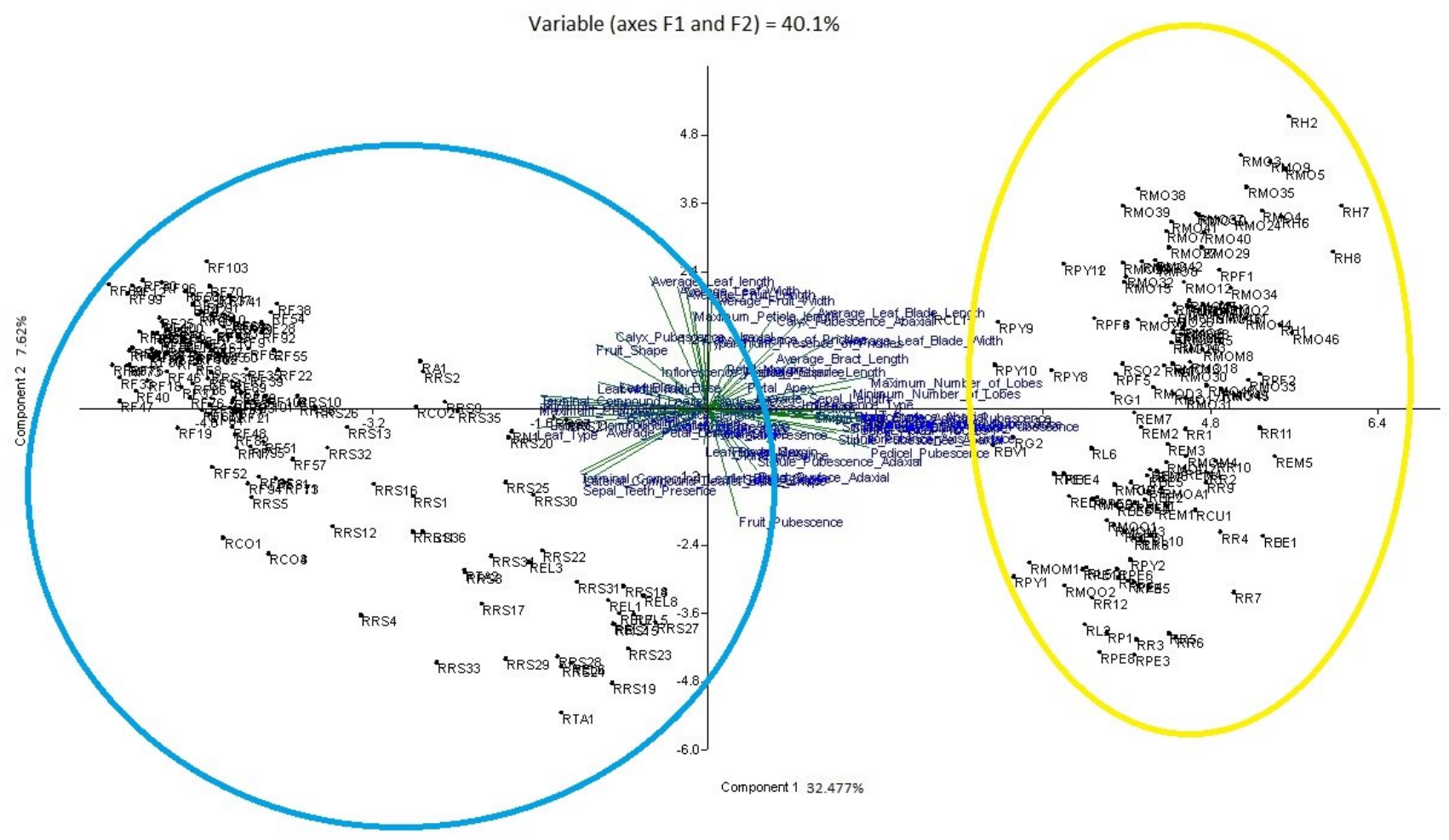

Figure 2. The visual output of the PCA Analysis of Philippine Rubus species showing axis 1 and 2.

rosifolius, and $R$. apoensis.

Zandee and Kalkman (1981) and Kalkman (1984) reduced a number of Rubus species in the Philippines into synonyms of $R$. rosifolius and $R$. rolfei. However, during the preliminary studies conducted using herbarium specimens, it was discovered that several species previously recognized as synonyms of $R$. rosifolius and $R$. rolfei have variations in morphological characters that could warrant their resurrection as recognized species.

English botanist Sir James Edward Smith first described $R$. rosifolius in 1791, based on a type specimen collected by Commerson from Mauritius. The species is present in continental Asia, Malesia, Hawaiian Islands, parts of Africa, and parts of South America. Merrill (1923) and Zandee and Kalkman (1981) reduced a number of species into synonyms of $R$. rosifolius. Merrill (1923) reduced $R$. comintanus Blanco and $R$. apoensis Elmer as synonyms of $R$. rosifolius while Zandee and Kalkman (1981) later reduced $R$. tagallus Cham. \& Schlecht. as another synonym of $R$. rosifolius. Zandee and Kalkman (1981) noted that $R$. rosifolius can be separated from other morphologically similar species in Malesia, including $R$. asper Wall and R. sumatranus Miquel by the presence of sessile stalked glands. This delimitation was later adapted by $\mathrm{Lu}$ and Boufford (2003) in their treatment of the Rubus species in the
Flora of China and Huang and $\mathrm{Hu}$ (2009) in their revision of the Taiwanese Rubus species. However, Huang and $\mathrm{Hu}$ (2009) noted that the $R$. rosifolius exhibits a wide range of morphological variation and there is a need for further investigation regarding the delimitation of the species.

Similar to what is observed in the cluster analysis, $R$. tagallus and $R$. apoensis (Fig. 5) were distributed within the group of $R$. rosifolius specimens, which suggests that the three species shared morphological similarities. This may also highlight the degree of variability observed among the specimens of $R$. rosifolius and it is important that additional morphological characters and other sources information should be studied.

Another group of Rubus species that warrants separate analysis is the group comprised of $R$. rolfei, $R$. pentalobus, and $R$. elmerii. $R$. elmerii formed a separate sub-cluster in the dendrogram formed by cluster analysis, while $R$. rolfei and $R$. pentalobus formed another sub-cluster. Aside from the clustering observed in the dendrogram, PCA was also used to identify the factors that delimit the three closely related species.

Based on the scatterplot formed by PCA, R. elmerii forms a group separate from $R$. rolfei (Fig. 6). Moreover, the specimen of $R$. pentalobus is located distant from the specimens of $R$. rolfei. This suggests that while the dendrogram may group the 


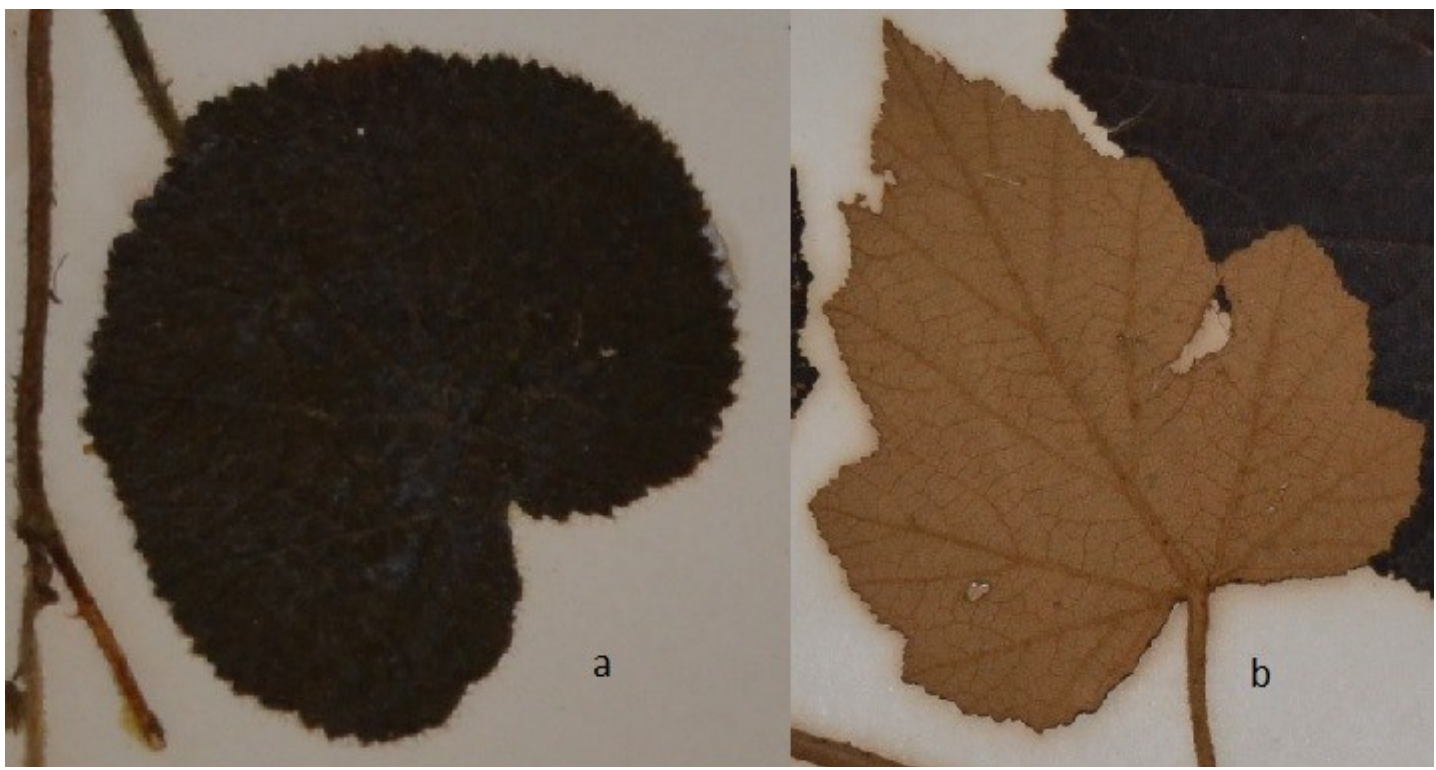

Figure 4. Number of lobes observed in Rubus leaves, showing no lobes (4a) and with five lobes (4b)

two species together, the two species differed sufficiently to be separated substantially in the scatterplot.

For these three species, the PC 1-6 provided significant ratio of the total variance, which amounted to $74.23 \%$ of the total variance. The first two axes of the PCA were responsible for $43.35 \%$ of the variation among the three species. The first axis explained $22.4 \%$ of the total variance, while the second axis explained $20.951 \%$ of the variance.

The score of the first axis was correlated with the fruit shape $(\mathrm{r}=0.9008)$, sepal apex, average petal length, sepal shape, and inflorescence position. Among the species, R. rolfei have orbicular fruits, while $R$. elmerii have ovoid fruits. Meanwhile, the second axis was correlated with the scores of average width of the leaf and the leaf blade, petiole length, and the average length of the leaf and the leaf blade. Among the species being studied, the second PC can be interpreted as the measurement of the average width of the leaf $(\mathrm{r}=0.8437)$, and based on the measurements of the specimens observed, $R$. rolfei had the widest leaf, followed by $R$. elmerii and $R$. pentalobus.

PCA was also performed on the specimens of $R$. moluccanus present in the Philippines (Fig. 7). Similar to what has been observed in the cluster analysis, the specimens of different varieties of $R$. moluccanus present in the Philippines were distributed across the scatterplot produced by PCA, and none of these varieties clustered together to form a grouping that only contains specimens from a specific variety. For example, specimens from $R$. moluccanus var. angulosus, $R$. moluccanus var. discolor, $R$. moluccanus var. moluccanus, and $R$. moluccanus var. obtusangulus can be found within the same cluster. This further emphasized the difficulty of distinguishing the varieties apart, especially with the presence of intermediate forms and varying descriptions of vegetative forms (Kalkman, 1984).

In addition to the cluster analysis, a phenogram was also constructed using the data gathered and aggregated from herbarium specimens and samples observed in the field. The strict consensus tree, which is displayed in Figure 6, was also generated from the equally most parsimonius trees. Out of the 76 morphological characters used in analysis, 72 were determined as informative for maximum parsimony analysis.

Even with the inclusion of additional morphological characters, there are still a number of observable similarities between dendrogram from cluster analysis and the dendrogram from the parsimony analysis (Figs. 1, 2, and 8). Similar to the results of the cluster analysis, the subgenus Malachobatus was clustered together along with $R$. pectinellus and $R$. pentalobus which is traditionally categorized under subgenus Chamaebatus. This clade was supported by the presence of simple leaves. Outside the clade formed by Rubus species with simple leaves were the species of Rubus with compound leaves. Unlike in UPGMA dendrogram, the species of Rubus with compound leaves did not form a well-supported cluster.

However, the clade of $R$. pectinellus and $R$. pentalobus was observed in the strict consensus tree, a grouping that was not observed in the cluster analysis of observed herbarium and field specimens. Instead, in the dendrogram, $R$. pentalobus was found to be clustered with $R$. rolfei. This clade, which represents what is traditionally recognized as subgenus Chamaebatus, is supported by reniform leaves, and solitary inflorescence. Moreover, according to earlier literature, this clade feature 


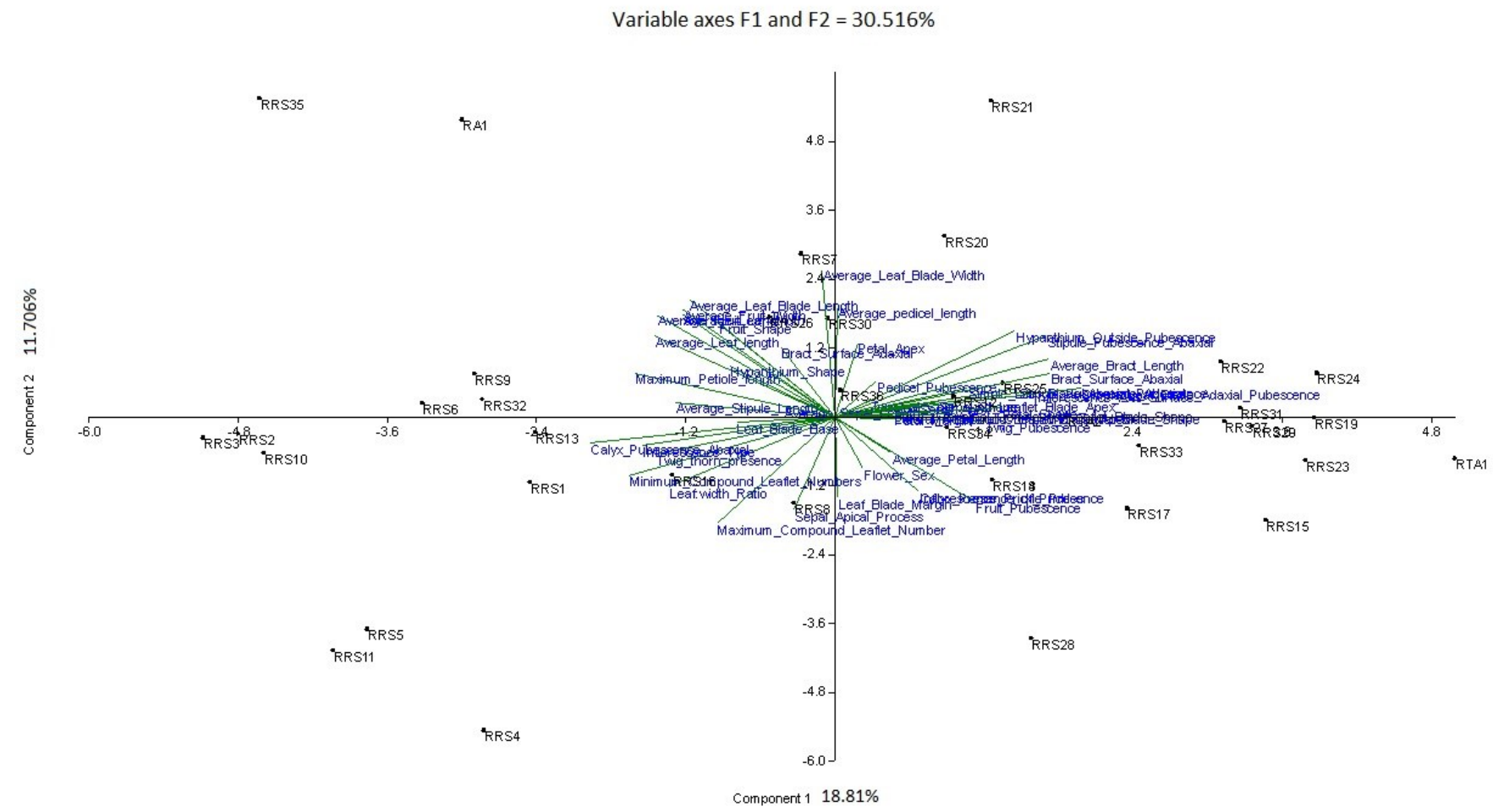

Figure 5. The visual output of the PCA Analysis of R. rosifolius, R. tagallus, and R. apoensis showing axis 1 and 2.

Variable axes F1 and F2 $=43.35 \%$

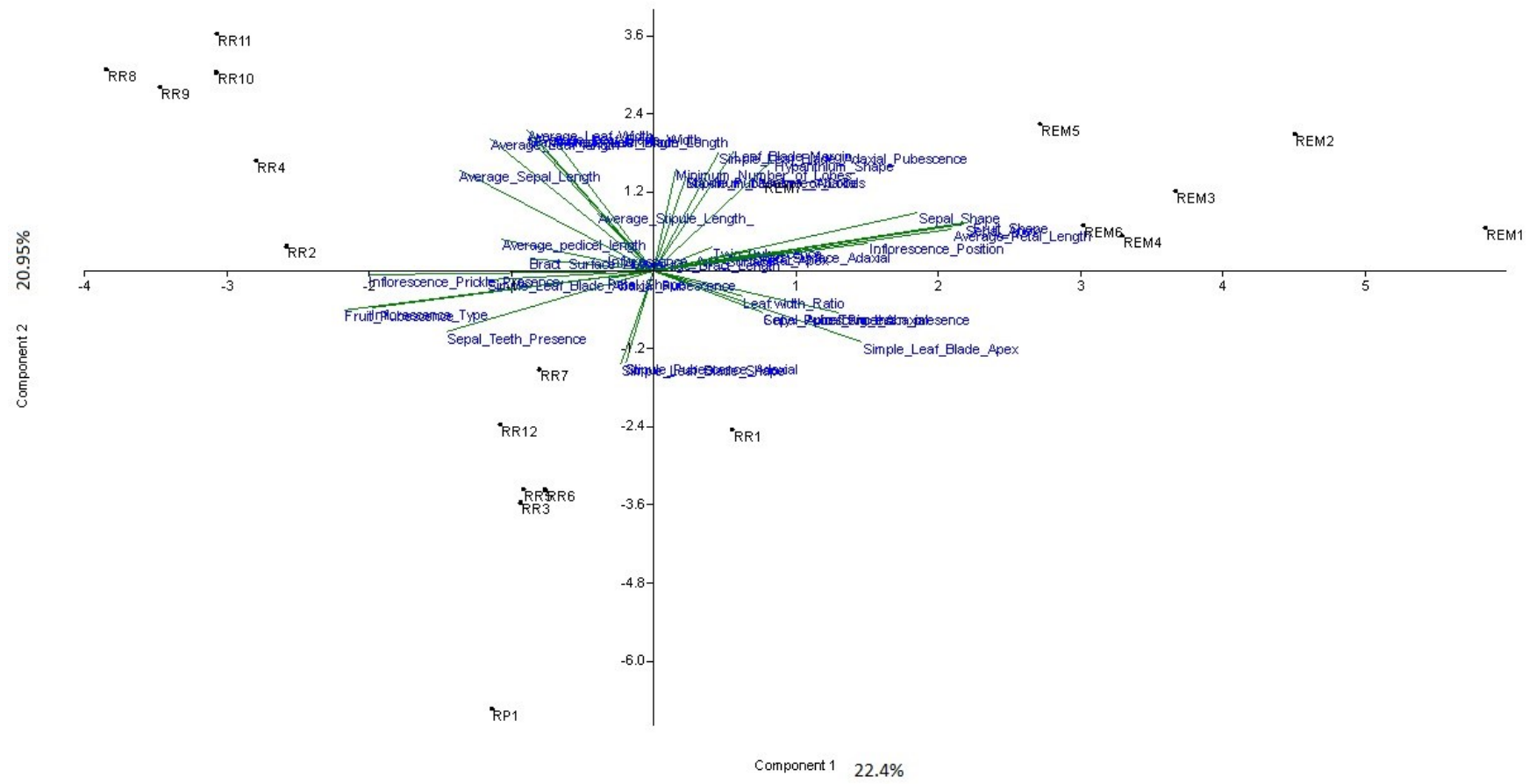

Figure 6. The visual output of the PCA Analysis of R. rolfei, R. elmeri and R. pentalobus. showing axis 1 and 2. 


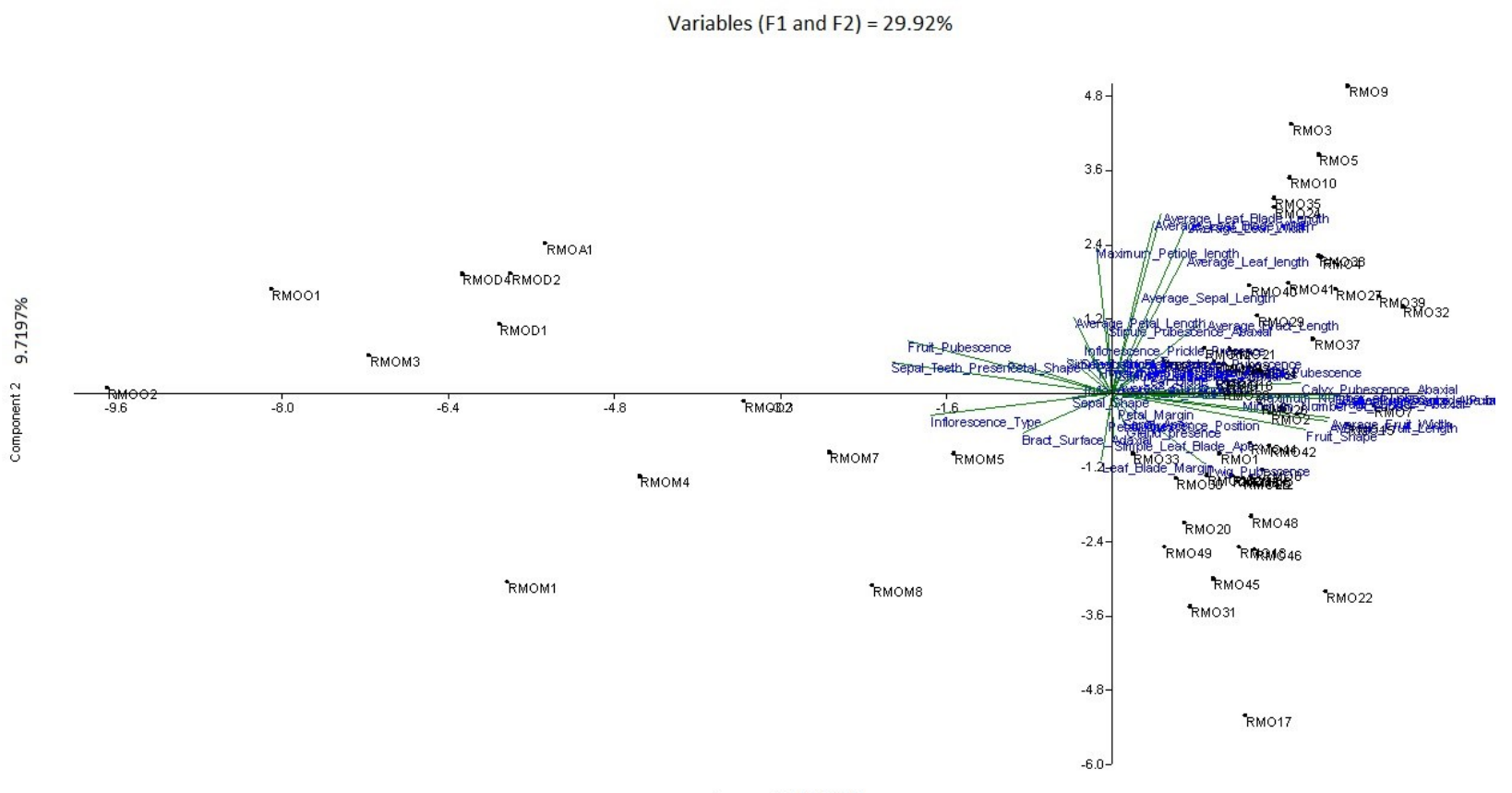

Figure 7. The visual output of the PCA Analysis of the different varieties of $R$. moluccanus showing axis 1 and 2.

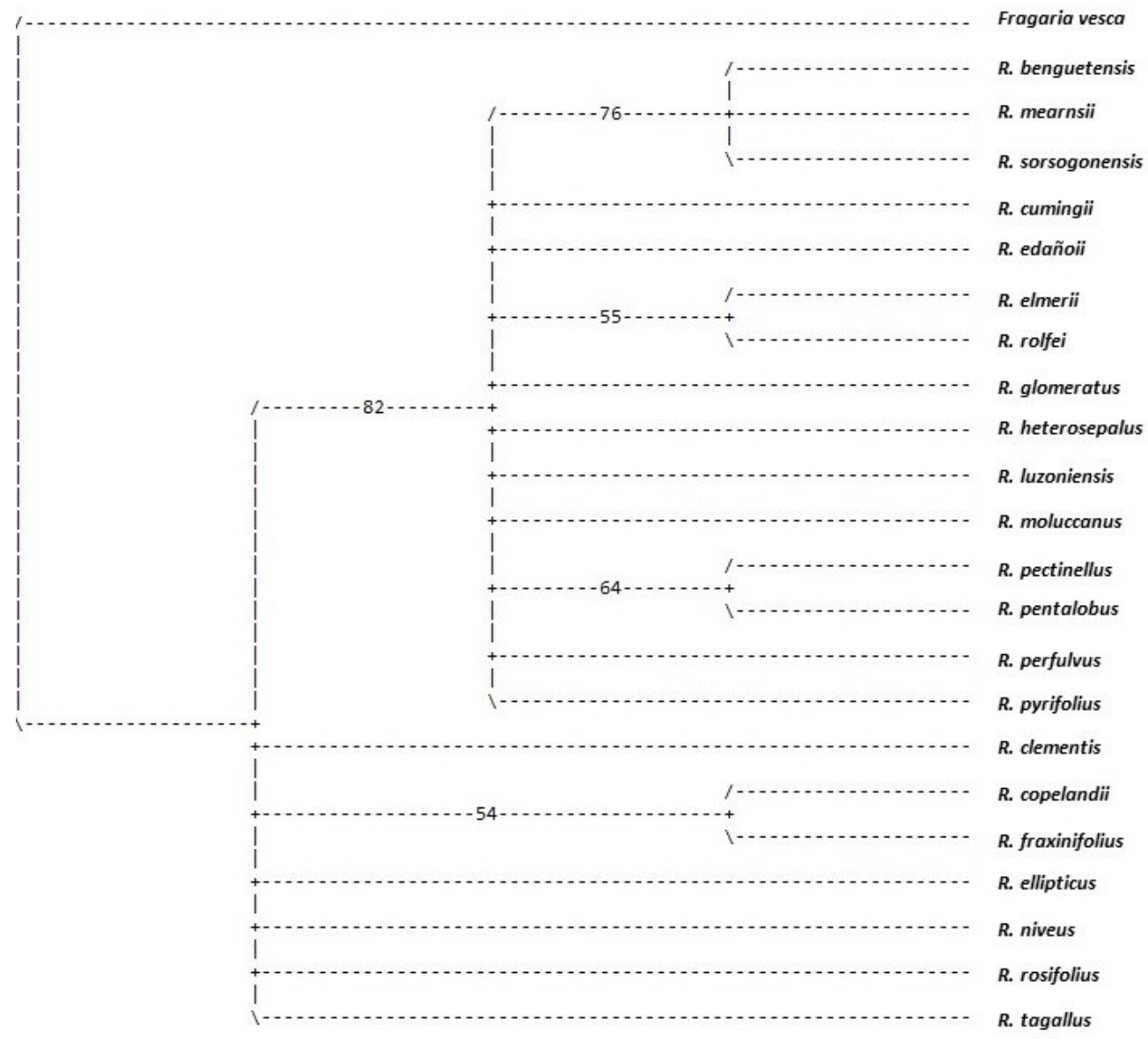

Figure 8. Strict consensus tree based on the morphological data of Rubus species in the Philippines based on 50\% majority-rule consensus tree. 
plants with $<1 \mathrm{~m}$ height ( $\mathrm{Lu}$ and Boufford, 2003). This clade was also united by the slightly pubescent twigs and pubescent adaxial bract surface, although the former was also observed in R. mearnsii while the latter was also observed in $R$. cumingii.

Another clade was formed by three species which included $R$. mearnsii, $R$. benguetensis, and $R$. sorsogonensis, and this clade was supported by the lack of petals. The lack of petals also affected other observed characteristics like the average length and width of the petals as well as the shape, margin, and apex of the petals. $R$. fraxinifolius and $R$. copelandii also formed a clade that is supported by elliptical leaflets, and it was separated from closely related species like $R$. rosifolius and $R$. tagallus.

Another clade that was well-supported in parsimony relationships is formed by $R$. elmeri and $R$. rolfei. $R$. elmeri was reduced by Kalkman (1984) as a synonym of $R$. rolfei, although cluster analysis using UPGMA did not cluster these two species together. These two species featured apically divided stipules and bracts, deeply divided leaves, and bullate leaf texture. However, the two species primarily differed in the inflorescence structure and habit, with $R$. rolfei having a compact simple raceme and shrub-like habit while $R$. elmeri having more elaborate compound raceme and subshrub habit.

The fourth clade was comprised by $R$. copelandii and $R$. fraxinifolius. These two species shared many similar character states, which include (ovate to) elliptical leaves, glabrous twigs, thyrse inflorescence, and abaxial surface of sepals with pubescence only at the margins. However, R. copelandii was distinguished through its ternate leaves, elliptical bracts and stipules, and presence of prickles at the hypanthium. In contrast, $R$. fraxinifolius had more leaflets, linear bracts and stipules, and lack of prickles.

\section{Conclusions and Recommendations}

Dendrogram produced by cluster analysis and groupings created by PCA provided insight on the taxonomic status of Rubus species present in the Philippines. While both the cluster analysis and the PCA did not fully distinguish the species, both methods separated the specimens from the subgenus Ideobatus into its own cluster. On the other hand, specimens from the subgenus Chamaebatus is clustered with the species from the subgenus Malachobatus, supporting the findings of the maximum parsimony tree formed from the descriptions of the Rubus species present in the Philippines.

In addition, the dendrograms also resolved a number of issues regarding the Rubus taxonomy at the species level. Cluster analysis of Rubus specimens showed that $R$. elmerii should be separated from $R$. rolfei. Furthermore, both PCA and cluster analysis show that varieties of $R$. moluccanus should be reduced as synonyms of $R$. moluccanus given the difficulty of distinguishing the specimens apart and the presence of intermediate forms, which prevent the delimitation of the species.

Numerous characters may also be used in delimiting the species of Rubus in the Philippines. Based on the scores obtained by morphological characters in the PCA, among the characters that can be used in classifying the species of Rubus or its clusters include the maximum number of lobes, pedicel pubescence, outside pubescence of the hypanthium, apex of the simple leaf blade, and the presence of sepal apical process. Other characters that could also be used in classifying the Rubus species in the country include the average length and width of the leaf and the fruit and the average leaf blade length.

\section{Acknowledgements}

The first author would like to thank the Department of Science and Technology - Science Education Institute for the financial support for this research. The authors would also like to thank the Philippine National Herbarium, University of the Philippines Los Baños - Museum of Natural History, University of the Philippines Diliman - Institute of Biology, University of Santo Tomas Herbarium, De La Salle University Herbarium, and the Central Mindanao University Herbarium for providing access to their specimens. The authors would also like to thank Dr. Esperanza Maribel Agoo for her assistance in the completion of this manuscript.

\section{Literature Cited}

Alice, L.A., \& C.S. Campbell, 1999. Phylogeny of Rubus (Rosaceae) based on nuclear ribosomal DNA internal transcribed spacer region sequences. American Journal of Botany, 86(1): 81-97

Carter, K.A., A. Liston, N.V. Bassil, L.A. Alice, J.M. Bushakra, B.L. Sutherland, T.C. Mockler, D.W. Bryant, \& K.E. Hummer, 2019. Target capture sequencing unravels Rubus evolution. Frontiers in Plant Science, 10:1616. https:// doi.org/10.3389/fpls.2019.01615

Elmer A.D.E., 1908. Synopsis of Rubus. In Elmer A.D.E (ed), Leaflets of Philippine Botany volume 2. Oriental Printing Co. Manila, Philippines. pp. 445-462

Elmer A.D.E., 1939. Miscellaneous new species. In Elmer A.D.E (ed), Leaflets of Philippine Botany volume 10. Oriental Printing Co. Manila, Philippines. pp. 3673-3810.

Elmer, A.D.E. \& W.O. Focke, 1913. Two new species of Rubus. In Elmer A.D.E (ed), Leaflets of Philippine Botany volume 
5. Oriental Printing Co. Manila, Philippines. pp. 16171623.

Focke W.O. 1914. Species Ruborum monographiae generis Rubi prodromus. Bibliotheca Botanica. 17: 121-223

Hammer Ø., D.A.T. Harper, \& P.D. Ryan, 2001. PAST: Paleontological statistics software package for education and data analysis. Palaeontologia Electronica, 4(1): 1-9.

Hayata B in G. Koidzumi, 1913. Conspectus Rosacearum Japonicarum. The Journal of the College of Science, Imperial University of Tokyo, 34(2): 1-312

Holub J., 1997. Some considerations and thoughts on the pragmatic classification of apomictic Rubus taxa. Osnabrücker Naturwissenschaftliche Mitteilungen 23: 147155

Howarth D.G., D.E. Gardner, \& C.W. Morden, 1997. Phylogeny of Rubus subgenus Ideobatus (Rosaceae) and its complications toward colonization of the Hawaiian Islands. Systematic Botany, 22: 443-441

Huang J. \& J. Hu, 2009. Revision of Rubus (Rosaceae) in Taiwan. Taiwania, 54(4): 285-310

Hummer K.E., 1996. Rubus Diversity. HortScience, 31(2): 182183

Jennings D.L., 1998. Raspberries and blackberries: Their breeding, diseases and growth. London: Academic Press.

Joly S. \& A. Bruneau, 2007. Delimiting species boundaries in Rosa Sect. Cinnamomeae (Rosaceae) in eastern North America. Systematic Botany, 32(4): 819-836

Kalkman, C., 1984. The genus Rubus (Rosaceae) in Malesia. 2. The subgenus Malachobatus. Blumea, 29: 319-386.

Kalkman, C., 1987. The genus Rubus (Rosaceae) in Malesia. 3. The subgenus Micranthobatus. Blumea, 32: 323-341.

Kalkman, C., 1993. Rubus. Flora Malesiana Ser. I Vol II (2): 247-285

Lu, L., and D.E. Boufford, 2003. Rubus L. In: Wu, Z.H. Raven, P.H. (Eds.) Flora of China, 9. Science Press, Beijing and Missouri Botanical Garden Press, St. Louis, USA, pp. 195286.

Madulid, D.A. and S.H. Sohmer. 1997. An update on the Flora of the Philippines project. In: Plant Diversity in Malesia III. Dransfield, J., M.J. E. Coode, and D.A. Simpson (eds). Royal Botanic Gardens, Kew, U.K

Marulanda, M, A.M. Lopez, and M. Uribe, 2012. Molecular characterization of the Andean blackberry, Rubus glaucus, using SSR markers. Genetics and Molecular Research 11 (1): $322-331$

Merrill, E.D., 1918. New or noteworthy Philippine plants XIII. Philippine Journal of Science, 13c: 1-66

Merrill, E.D., 1922. New or noteworthy Philippine plants XVII. Philippine Journal of Science, 20: 367-476
Merrill, E.D., 1923. An Enumeration of Philippine Flowering Plants. Manila: Bureau of Science

Naruhashi N., Iwatsubo Y., and Peng C.I., 2002. Chromosome numbers in Rubus (Rosaceae) of Taiwan. Botanical Bulletin of the Academia Sinica, 43: 193-201.

Šarhanova P., Vašut R. J., Dančak M., Bureš P. \& Travniček B., 2012. New insights into the variability of reproduction modes in European populations of Rubus subgen. Rubus: how sexual are polyploid brambles? - Sexual Plant Reproduction, 25: 319-335.

Swofford, D.L. 2001. PAUP*: Phylogenetic analysis using parsimony and other methods. Sinauer Associates, Sunderland, MA. http://paup.csit.fsu.edu/

Zandee, M., and C. Kalkman, 1981. The genus Rubus (Rosaceae) in Malesia 1. Subgenera Chamaebatus and Ideobatus. Blumea, 27: 75-113 